\title{
Efeito de diferentes sistemas de pastejo sobre o desempenho de suínos mantidos em pastagem de trevo-branco (Trifolium repens L.) ${ }^{1}$
}

\section{Denyse Maria Galvão Leite ${ }^{2}$, Marcelo Abreu da Silva ${ }^{3}$, Renato Borges de Medeiros ${ }^{3}$, João Carlos de Saibro ${ }^{3}$, Marcos Antonio Pavan ${ }^{4}$, Marcos Aurélio Arrighi Barrey ${ }^{5}$}

${ }^{1}$ Trabalho financiado pelo CNPq - Programa Plano Sul de Pesquisa em Pós-Graduação.

2 Instituto Agronômico do Paraná/IAPAR - Cx. Postal 510, CEP: 85505-970, Pato Branco - PR.

${ }^{3}$ Faculdade de Agronomia, Universidade Federal do Rio Grande do Sul - Cx. Postal 15100, CEP: 90001-970, Porto Alegre - RS.

${ }^{4}$ Instituto Agronômico do Paraná/IAPAR - Cx. Postal 481, CEP 86001-970, Londrina - PR.

${ }^{5}$ Bolsista de Extensão Rural - Estudante da Faculdade de Agronomia da UFRGS, Porto Alegre.

\begin{abstract}
RESUMO - Este estudo foi conduzido com o objetivo de avaliar o efeito dos sistemas de pastejo contínuo, alternado e rotativo sobre as características de desempenho de suínos (consumo de ração, ganho de peso, conversão alimentar e espessura de toucinho) nas fases de crescimento e terminação mantidos em pastagem de trevo-branco (Trifolium repens L.). Foram realizadas também avaliações da disponibilidade e composição química da pastagem. Trinta e seis suínos machos foram distribuídos em um delineamento de blocos casualizados, com três tratamentos e três repetições, e doze foram mantidos em sistema de confinamento. Não foi observada influência significativa dos sistemas de pastejo sobre as características de desempenho dos animais e a disponibilidade de forragem. Entretanto, houve diferença significativa na composição química da pastagem entre os sistemas de pastejo estudados. Os suínos em sistemas de pastejo contínuo, alternado e rotativo consumiram de 13,41 a $15,92 \%$ a menos de ração e apresentaram menores ganhos de peso e espessura de toucinho que aqueles criados em confinamento. Não foram registradas diferenças significativas na conversão alimentar entre os suínos mantidos em confinamento e em pastagem.
\end{abstract}

Palavras-chave: confinamento, forragem, pastagem, sistema de pastejo

\section{Effect of different grazing systems on the performance of pigs, in growing and finishing phases, kept on white clover (Trifolium repens $L$.) pasture}

\begin{abstract}
This trial was carried out to determine the effect of continuous, alternated or rotational grazing systems on the performance of pigs (feed intake, weight gain, feed conversion and backfat thickness), in the growing and finishing phases, as well as the forage availability and chemical composition of a white clover pasture (Trifolium repens L.). Thirtysix castrated pigs were allotted to a randomized complete-block experimental design with three treatments and three replications. Twelve feedlot pigs were kept on a rearing system. No significant differences were found between grazing systems on parameters of animal performance and forage on offer. However, significant differences were observed on the pasture chemical composition between the grazing systems studied. Pigs reared on white clover pasture consumed from 13.41 to $15.92 \%$ less feed and showed smaller backfat thickness and weight gain than pigs reared in the confined system. No significant differences on feed conversion between feedlot pigs and pigs under pasture conditions were observed.
\end{abstract}

Key Words: feedlot, forage, grazing system, pasture

\section{Introdução}

Desde o início de seu processo de domesticação, os suínos são criados ao ar livre. Nesta situação, eram criados em grandes áreas com alimentação à base de forragens, frutos e raízes. Com a intensificação da agricultura, as criações extensivas foram rapidamente substituídas por sistemas de confinamento, nos quais os animais são alimentados com rações comerciais, formuladas com alimentos concentrados. Estas criações permitiram grandes aumentos produtivos e diferentes avanços tecnológicos, mas apresentam problemas, principalmente relacionados ao alto custo de produção, ao manejo dos dejetos e à competição entre a alimentação humana e animal, tendo em vista suas principais fontes energéticas e protéicas, como o milho e o farelo de soja. Diante desses problemas, os produtores têm sido pressionados a buscar alternativas tecnológicas sustentáveis que assegurem a qualidade de seus produtos, em resposta às exigências de mercado, e reduzam o impacto ambiental. 
Algumas alternativas foram propostas, entre as quais, o sistema de criação de suínos a campo, utilizado nos anos 50 e 60 e resgatado desde o final da década de 80 , principalmente por seu baixo custo de implantação em relação aos sistemas convencionais. Desde então, esse sistema tem sido implantado como atividade isolada (em bosques, florestas, campos nativos) ou integrada com sistemas agrícolas em restevas ou pastagens cultivadas.

Nas modernas criações de suínos a campo, as pastagens são utilizadas quase que exclusivamente para proteger o solo do pisoteio dos suínos e evitar problemas de compactação e erosão. Todavia, com o resgate de conhecimentos existentes sobre este tipo de criação e diante de novas informações, surge a possibilidade de se valorizar a utilização de pastagens como alternativa alimentar para estes animais.

Segundo Mott \& Barnhart (1966), suínos têm capacidade de consumir pastagens e parte de suas exigências nutricionais pode ser atendida mediante o consumo de forrageiras de boa qualidade nutricional. A contribuição nutricional da pastagem depende de sua disponibilidade, composição química, ingestão e digestibilidade, que, por sua vez, são influenciadas pelo manejo ao qual está submetida a pastagem. Neste sentido, Vicenzi (1996) afirma que o pastejo rotativo é o mais eficiente sistema de utilização das pastagens por bovinos, ovinos e eqüinos. Sório (2003) propõe que o método mais eficaz de estimular o apetite dos animais consiste no aumento da freqüência de trocas de piquetes.

Apesar do grande potencial da utilização de pastagens na alimentação de suínos criados ao ar livre, são poucas as informações disponíveis na literatura. No caso da Região Sul do Brasil, onde o conhecimento sobre este tipo de sistema é praticamente inexistente, verifica-se grande necessidade de desenvolvimento de estudos visando à obtenção de informações que contribuam para a adequação do uso de pastagens em criações de suínos, de forma a torná-lo mais uma alternativa produtiva para o setor suinícola.

Neste sentido, o objetivo neste trabalho foi avaliar o desempenho de suínos mantidos em pastagem de trevobranco (Trifolium repens L.) em sistemas de pastejo contínuo, alternado e rotativo.

\section{Material e Métodos}

O presente estudo foi realizado durante o período de 28/09/2002 a 21/11/2002, na Estação Experimental de Pato Branco do Instituto Agronômico do Paraná(EEPB/IAPAR), situada na região Sudoeste do Estado do Paraná, com coordenadas $26^{\circ} 07^{\prime} \mathrm{S}$ e $52^{\circ} 41^{\prime} \mathrm{W}$ e altitude de $700 \mathrm{~m}$. O clima da região é subtropical úmido do tipo fundamental $\mathrm{Cfa}$, conforme classificação climática de Köppen.
O experimento foi realizado em uma área de $5.400 \mathrm{~m}^{2}$, anteriormente cultivada com milho (Zea mays). Para o plantio do trevo-branco, foi utilizada uma semeadeira a lanço e, depois, uma grade de discos aberta para cobrir as sementes. Foram utilizados $3 \mathrm{~kg}$ de sementes por hectare, as quais foram inoculadas e peletizadas antes do plantio.

Foram utilizados 36 suínos híbridos, machos castrados, resultantes do acasalamento de fêmeas Large White $\mathrm{x}$ Landrace e machos Duroc.

Os suínos foram identificados individualmente na orelha por meio do sistema australiano de marcação e divididos em grupos estratificados por peso, formados cada um por quatro animais. Os grupos foram distribuídos em um delineamento de blocos casualizados, com três repetições e três tratamentos:

$\mathrm{T} 1$ = animais em pastejo contínuo na totalidade da área durante todo o período experimental;

$\mathrm{T} 2$ = animais sob pastejo alternado em dois subpiquetes;

$\mathrm{T} 3=$ animais sob pastejo rotativo em quatro subpiquetes - enquanto um subpiquete era pastejado, os outros três permaneciam em descanso.

Paralelamente ao experimento realizado no campo, 12 suínos foram mantidos em sistema de confinamento, divididos em três grupos, cada um formado por quatro animais com as mesmas características daqueles utilizados na criação a campo. Os dados de desempenho destes animais foram comparados aos dos mantidos em pastagem de trevo-branco nos diferentes sistemas de pastejo estudados.

Os suínos mantidos em confinamento foram também identificados individualmente por meio do sistema australiano de marcação, e, após a aplicação de anti-helmínticos, foram transferidos para baias de alvenaria $(4 \times 4 \mathrm{~m})$ com piso de concreto semi-ripado, onde tinham acesso livre à água e recebiam ração à vontade.

A área destinada à criação de suínos a campo foi dividida em nove piquetes de tamanho similar $\left(600 \mathrm{~m}^{2}\right)$, onde foram colocados quatro animais por piquete, em densidade de $150 \mathrm{~m}^{2}$ /animal. Os piquetes destinados ao pastejo rotativo foram divididos em quatro subpiquetes de mesmo tamanho e aquele destinado ao pastejo alternado foi dividido em dois.

Para demarcação dos piquetes e dos subpiquetes, foram utilizados fios eletrificados dispostos a 20 e a $60 \mathrm{~cm}$ do solo. Cada piquete dispunha de um comedouro de madeira com cobertura de zinco, um abrigo rústico $(3 \times 3 \mathrm{~m})$ e bebedouros tipo chupeta instalados em cada subpiquete, no caso do tratamento rotativo e alternado.

Antes de os animais serem transferidos para o campo, realizou-se o argolamento ou destrompe, que consiste na inserção de uma argola de arame sob a cartilagem nasal dos animais, visando atenuar o hábito de fuçar dos suínos. 
Após a aplicação de anti-helmínticos, os animais (média de $27 \mathrm{~kg}$ de PV) foram colocados na pastagem de trevobranco quando a disponibilidade média de forragem era de $1.923,28 \mathrm{~kg} \mathrm{MS} / \mathrm{ha}$ e mantidos no campo até atingirem peso de abate ( 90 a $100 \mathrm{~kg}$ de PV). Durante o período experimental, a oferta de forragem foi monitorada por meio da técnica de put and take (Moot \& Lucas, 1952), de forma a permitir que a disponibilidade se mantivesse entre $1.000 \mathrm{e} 2.000 \mathrm{~kg} \mathrm{MS} / \mathrm{ha}$. A partir deste procedimento, foi possível adotar os seguintes períodos de descanso e de utilização dos piquetes:

- pastejo alternado $=15$ dias de utilização e 15 dias de descanso;

- pastejo rotativo $=7$ a 10 dias de utilização e 21 a 30 dias de descanso.

As rações foram formuladas de acordo com as exigências nutricionais de suínos nas fases de crescimento e terminação em sistema de confinamento (NRC, 1998). Os animais tinham livre acesso à água e à pastagem de trevo-branco e recebiam ração à vontade.

Os dados de desempenho foram obtidos a partir dos registros de peso dos animais e do consumo de ração, feitos a cada 15 dias, efetuando-se a retirada da ração dos comedouros e da pesagem da sobra 12 horas antes da pesagem. A partir destas informações, foi possível calcular os consumos diário (CDR) e total de ração (CTR), os ganhos de peso diário (GPD) e total (GPT) e a conversão alimentar (CA). O peso final (PF) e a espessura de toucinho (ET) também foram avaliados.

As determinações da espessura de toucinho foram realizadas no ponto $\mathrm{P} 2$ - entre a última e a penúltima costelas, a 6,5 cm da coluna vertebral (Roppa, 1991) - utilizando-se um medidor ultra-sônico de gordura, efetuando-se duas medições por animal, uma do lado direito e outra do lado esquerdo da vértebra.

A disponibilidade de forragem foi estimada pela técnica de dupla amostragem (Haydock \& Shaw, 1975) a cada 15 dias pelo método de cortes e leituras de disco (Gardner, 1986), utilizando-se equipamento constituído por uma haste metálica graduada, ao longo da qual um disco galvanizado com área de $0,0553 \mathrm{~m}^{2}$ desloca-se em movimento ascendente perpendicular ao solo.

A transformação das leituras de disco em disponibilidade de forragem foi feita por meio de equação de regressão (Frame, 1981) desenvolvida a partir das amostragens da população, realizadas por medidas diretas (cortes) e indiretas (leituras de disco) tomadas em cada uma das amostras (Dobashi et al., 2001). Foram escolhidas aleatoriamente quatro amostras, em cada piquete onde foram realizados a medida da leitura do disco, a qual se encontrava na projeção vertical do disco, e o corte da pastagem, rente ao solo. Depois dos cortes, foram feitas mais 20 leituras aleatórias com disco em cada piquete, a fim de se proceder à estimativa de disponibilidade média de forragem do piquete.

As avaliações de disponibilidade de forragem foram feitas na ocasião das pesagens dos animais, observando-se que, nos tratamentos 2 e 3 , foram realizadas também nos subpiquetes em período de descanso mais prolongado.

A forragem verde obtida a cada corte foi acondicionada em sacos de papel e seca em estufas a $65^{\circ} \mathrm{C}$ por 72 horas (Haydock \& Shaw, 1975). Após este processo, as amostras secas foram pesadas e submetidas às análises bromatológicas. A partir destas amostras, foram determinados os teores de PB, FDN, FDA, hemicelulose, celulose e lignina da forragem disponível.

Os dados de desempenho dos animais e da disponibilidade e composição da forragem foram submetidos à análise de variância por meio do programa estatístico SAS (1996), segundo o modelo matemático:

$$
\mathrm{Y}_{i j k}=\mu+\mathrm{T}_{i}+\mathrm{B}_{j}+\varepsilon_{i j k}
$$

em que: $\mathrm{Y}_{i j k}=$ variável dependente; $\mu=$ média geral; $\mathrm{T}_{i}=$ efeito do tratamento de índice $\mathrm{i} ; \mathrm{B}_{j}=$ efeito do bloco de índice j; e $\varepsilon_{i j k}=$ erro aleatório associado a cada observação.

As variáveis PF, CDR, CTR e CA foram analisadas considerando-se no modelo matemático o peso médio inicial (PMI) como covariável. As médias foram comparadas pelo teste $t$-Student.

Foi também realizado o teste $t$-Student para comparação das médias dos dados de desempenho dos suínos mantidos nos sistemas de pastejo e confinamento.

\section{Resultados e Discussão}

Na Tabela 1 são apresentadas as médias e os errospadrão das variáveis peso final (PF), ganho de peso total (GPT), ganho de peso diário (GPD), consumo total de ração (CTR), consumo diário de ração (CDR), conversão alimentar (CA) e espessura de toucinho (ET) dos suínos criados a campo e em confinamento.

Não foram observadas diferenças significativas $(\mathrm{P}>0,05)$ das características de desempenho entre os sistemas de pastejo contínuo, alternado e rotativo.

De acordo com os estudos de Bridi et al. (2003) e Both (2003), o consumo de forragem influencia o consumo de ração. Portanto, como neste estudo não houve diferenças significativas $(\mathrm{P}>0,05)$ no consumo voluntário de ração entre os sistemas de pastejo estudados, tendência semelhante pode ter ocorrido no consumo de pastagem, o que provavelmente está relacionado ao fato de os sistemas de pastejo estudados não apresentarem diferenças significativas 
Tabela 1 - Media e erros-padrão das caraterísticas de desempenho de suínos em crescimento e terminação criados em pastagem de trevo-branco em sistemas de pastejo contínuo, alternado e rotativo

Table 1 - Means and standard errors of pigs performance during the growing and finising phases, reared under white clover pasture on the contiuous, alternated and rotational grazing systems

\begin{tabular}{|c|c|c|c|c|c|c|c|}
\hline $\begin{array}{l}\text { Tratamento } \\
\text { Treatment }\end{array}$ & $\begin{array}{c}\mathrm{PF}^{*}(\mathrm{~kg}) \\
F W(\mathrm{~kg})\end{array}$ & $\begin{array}{c}\mathrm{GPT}^{*}(\mathrm{~kg}) \\
T W G(\mathrm{~kg})\end{array}$ & $\begin{array}{c}\mathrm{GPD}^{*}(\mathrm{~kg}) \\
D W G(\mathrm{~kg})\end{array}$ & $\begin{array}{c}\mathrm{CTR}^{*}(\mathrm{~kg}) \\
\text { TFI }(\mathrm{kg})\end{array}$ & $\begin{array}{c}\mathrm{CDR}^{*}(\mathrm{~kg}) \\
D F I(\mathrm{~kg})\end{array}$ & $\begin{array}{l}\mathrm{CA}^{*} \\
F C\end{array}$ & $\begin{array}{c}\mathrm{ET}^{*}(\mathrm{~mm}) \\
B T\end{array}$ \\
\hline $\begin{array}{l}\text { Confinamento } \\
\text { Feedlot }\end{array}$ & $105,9^{\mathrm{a}} \pm 2,35$ & $79,5^{\mathrm{a}} \pm 2,4$ & $0,97^{\mathrm{a}} \pm 0,03$ & $231,1^{\mathrm{a}} \pm 7,20$ & $2,82^{\mathrm{a}} \pm 0,88$ & $2,90^{\mathrm{a}} \pm 0,77$ & $21,30^{a} \pm 1,18$ \\
\hline $\begin{array}{l}\text { Pastejo contínuo } \\
\text { Continuous grazing }\end{array}$ & $93,4^{\mathrm{Ab}_{ \pm 2}, 35}$ & $66,1^{\mathrm{Ab}_{ \pm 2,4}}$ & $0,81^{\mathrm{Ab}_{ \pm 0}, 03}$ & $194,3^{\mathrm{Ab}_{ \pm}}+20$ & $2,37^{\mathrm{Ab}_{ \pm} 0,88}$ & $2,94^{\mathrm{Aa}_{ \pm} 0,77}$ & $15,40^{\mathrm{Ab}_{ \pm} 1,18}$ \\
\hline $\begin{array}{l}\text { Pastejo alternado } \\
\text { Alternated grazing }\end{array}$ & $95,8^{\mathrm{Ab}_{ \pm 2}, 35}$ & $68,4^{\mathrm{Ab}} \pm 2,4$ & $0,83^{\mathrm{Ab}_{ \pm 0}, 03}$ & $200,1^{\mathrm{Ab}_{ \pm 7}, 20}$ & $2,44^{\mathrm{Ab}} \pm 0,88$ & $2,92^{\mathrm{Aa}_{ \pm}}+77$ & $18,17^{\mathrm{Ab}} \pm 1,18$ \\
\hline $\mathrm{CV}^{* *}$ & 4,21 & 6,00 & 5,99 & 6,08 & 6,08 & 4,55 & 11,57 \\
\hline
\end{tabular}

a,b Médias seguidas de letras distintas, na mesma coluna, apresentam diferença significativa $(P<0,05)$.

$a, b \quad$ Means followed by the different letters, in the same coluumn, statistically differ $(P<0,05)$.

$A, B$ Médias seguidas de letras semelhantes, na mesma coluna, não apresentam diferença significativa $(P>0,05)$.

$A, B$ Means followed by the same letters, in the same coluumn, not statistically differ $(P>0,05)$.

PF - peso final, GPT - ganho de peso total, GPD - ganho de peso diário, CTR - consumo total de ração, CDR - consumo diário de ração, CA - conversão alimentar e ET - espessura de toucinho.

CV - coeficiente de variacão

FW - final weight, TWG - total weight gain, DWG - daily weight gain, TFI - total feed intake, DFI - daily feed intake, FC - feed conversion and BT - backfat thickness.

CV-coefficient of variation.

Tabela 2 - Estimativas de disponibilidade da pastagem de trevobranco em sistema de pastejo rotativo, alternado e contínuo

Table 2 - Estimates of forage availability of white clover pasture on the rotational, alternated and continuous grazing systems

$\begin{array}{lr}\text { Tratamento } & \mathrm{kg} \mathrm{MS} / \mathrm{ha} \\ \text { Treatment } & \mathrm{kg} \mathrm{DM/ha}\end{array}$

Pastejo contínuo $1603,23 \pm 25,92^{\text {a }}$

Continuous grazing

Pastejo alternado

$1603,03 \pm 25,92^{\mathrm{a}}$

Alternated grazing

Pastejo rotativo

Rotational grazing

$\bar{a}$ Médias seguidas de letras semelhantes, na mesma coluna, não apresentam diferença significativa $(P>0,05)$.

${ }^{a}$ Means followed by the same letters, in the same column, not statistically differ $(P>0.05)$.

$(\mathrm{P}>0,05)$ de disponibilidade de forragem (Tabela 2) e, apesar das diferenças significativas nos teores de $\mathrm{PB}$ e FDA $(\mathrm{P}<0,05)$ entre os sistemas de pastejo, a pastagem de trevo-branco apresentouse com boa qualidade nutricional (baixo teor de fibra e alto de proteína)nos diferentes sistemas de pastejo avaliados(Tabela3).

Segundo Andresen \& Redbo (1999), o consumo de forragem por suínos nas fases de crescimento e terminação pode ser influenciado pelo tempo que os animais permanecem em determinada área. Stern \& Andresen (2003), ao manejarem suínos em fase de terminação com pastoreio em faixa, observaram que as sucessivas locações de novas áreas estimularam o pastejo dos animais, o que não foi observado nos suínos nos sistemas de pastejo alternado e rotativo. Portanto, os períodos de utilização dos piquetes adotados neste estudo não foram eficientes para estimular o consumo de pastagem.

Foram observadas diferenças significativas $(\mathrm{P}<0,05)$ entre as caraterísticas de desempenho dos suínos criados a campo e em confinamento. Suínos criados em pastagem de trevo-branco submetido a diferentes sistemas de pastejo, apresentaram menores PF, GPT, GPD e ET e consumiram menos ração $(\mathrm{P}<0,05)$ que aqueles criados em confinamento. Não houve diferenças significativas entre a conversão alimentar $(\mathrm{P}>0,05)$ de suínos criados em pastagem e a dos criados em confinamento (Tabela 1).

No Brasil, Lavorenti et al. (1980) e Irgang et al. (1992) verificaram resultados diferentes dos obtidos neste estudo, pois não notaram diferenças significativas entre os ganhos de peso dos suínos criados em pastagem de coastcross (Cynodon spp.) e dos criados em confinamento. Entretanto, Bridi et al. (2003), Guy (2002) e Both (2003) observaram resultados semelhantes aos observados neste estudo.

Quanto à conversão alimentar, Irgang et al. (1992), Guy et al. (2002) e Both (2003) observaram que suínos criados em pastagem apresentaram melhor conversão alimentar que aqueles em confinamento, o que contraria os resultados obtidos neste estudo.

Alguns autores (Irgang et al., 1992; Bridi et al., 2003; Both, 2003) verificaram que suínos criados em pastagem de coastcross (Cynodon spp.) e em campo nativo melhorado com ração à vontade consumiram 5 a $28 \%$ menos ração que os suínos provenientes do sistema de confinamento. Neste estudo, os animais em pastejo contínuo, alternado e rotativo consumiram 15,92; 13,41 e 15,88\%, respectivamente, menos ração que aqueles criados em confinamento.

Segundo Both (2003), o menor consumo de ração dos suínos criados em pastagem provavelmente está relacionado ao fato de esses suínos saciarem a fome ao ingerirem pastagem rica em fibra. 
Tabela 3 - Composição química da pastagem de trevo-branco em sistemas de pastejo contínuo, alternado e rotativo Table 3 - Chemical composition of white clover pasture on the continuos, alternated and rotational grazing systems

\begin{tabular}{lccc}
\hline $\begin{array}{l}\text { Componente } \\
\text { Component }\end{array}$ & \multicolumn{2}{c}{$\begin{array}{c}\text { Tratamento } \\
\text { Treatment }\end{array}$} \\
\cline { 2 - 4 } & $\begin{array}{c}\text { Pastejo contínuo } \\
\text { Continuous grazing }\end{array}$ & $\begin{array}{c}\text { Pastejo alternado } \\
\text { Alternated grazing }\end{array}$ & $\begin{array}{c}\text { Pastejo rotativo } \\
\text { Rotational grazing }\end{array}$ \\
\hline PB (CP), \% & $25,61 \pm 0,32^{\mathrm{a}}$ & $24,87 \pm 0,32^{\mathrm{b}}$ & $24,41 \pm 0,32^{\mathrm{b}}$ \\
FDN (NDF), \% & $45,34 \pm 1,65$ & $43,13 \pm 1,65$ & $42,93 \pm 1,65$ \\
FDA (ADF), \% & $28,65 \pm 0,63^{\mathrm{b}}$ & $30,41 \pm 0,63^{\mathrm{a}}$ & $31,25 \pm 0,63^{\mathrm{a}}$ \\
Hemicelulose (Hemicellulose), \% & $15,34 \pm 0,56$ & $14,87 \pm 0,56$ & $14,35 \pm 0,56$ \\
Lignina (Lignin), \% & $9,38 \pm 0,39$ & $9,14 \pm 0,39$ & $9,75 \pm 0,39$ \\
Celulose (Cellulose), \% & $19,26 \pm 0,47$ & $19,88 \pm 0,47$ & $19,61 \pm 0,47$ \\
\hline
\end{tabular}

a,b Médias seguidas de letras diferentes, na mesma linha, apresentam diferença significativa $(P<0,05)$.

$a, b$ Means followed by the different letters in the same row differ $(P<0.05)$.

Apesar da boa qualidade nutricional da forragem, sugere-se que sua ingestão pelos suínos não foi suficiente para atender às exigências nutricionais dos animais, resultando, conseqüentemente, em menores ganhos de peso em comparação ao sistema de confinamento. Entretanto, é importante salientar que a pastagem teve participação efetiva na dieta do suíno, comparada pelos dados de conversão alimentar nos diferentes sistemas de pastejo. Neste estudo, para se obter um quilo de peso vivo, os suínos criados em pastagem consumiram a mesma quantidade de ração que aqueles em confinamento. Porém, como os suínos mantidos em pastagem são mais ativos e gastam mais energia para atividade de locomoção (Stern \& Andresen, 2003), parte das exigências nutricionais foi atendida pela ingestão da pastagem.

\section{Conclusões}

Suínos criados em pastagem consumiram menos ração que aqueles criados em confinamento e apresentaram menores ganhos de peso.

Os sistemas de pastejo estudados não influenciaram o desempenho de suínos criados ao ar livre.

\section{Literatura Citada}

ANDRESEN, N.; REDBO, I. Foraging behaviour of growing pigs on grassland in relation to stocking and feed crude protein level. Applied Animal Behaviour Science, v.62, n.2-3, p.183-197, 1999.

BRIDI, A.M.; NICOLAIEWSKY, S.; RÜBENSAM, J.M. Efeito do genótipo halotano e de diferentes sistemas de produção no desempenho produtivo e na qualidade da carcaça suína. Revista Brasileira de Zootecnia, v.32, n.4, p.942-950, 2003.

BOTH, M.C. Comportamento e produção de suínos mantidos em pastagem e submetidos a diferentes níveis de restrição alimentar. Porto Alegre: Universidade Federal do Rio Grande do Sul, 2003. 127p. Tese (Doutorado) - Universidade Federal do Rio Grande do Sul, 2003.

DOBASHI, A.F.; PENATI, M.A.; BARONI, L.G. et al. Avaliação de três métodos indiretos para a determinação de massa de forragem em pastagem rotacionada de Panicum maximum cv. Tanzânia em diferentes níveis de resíduo sob irrigação (compact disc.). In: REUNIÃO ANUAL DA SOCIEDADE BRASILEIRA DE
Zootecnia, 38., 2001, Piracicaba. Anais... Piracicaba: Sociedade Brasileira de Zootecnia, 2001.

FRAME, J. Herbage mass. In: HODGSON, J.; BAKER, R.D; DAVIES, A. et al. (Eds.) Sward mensurament handbook. Berkshire: Bristish Grassland Society, 1981. p.39-67.

GARDNER, A.L. Técnicas de pesquisa em pastagens e aplicabilidade de resultados em sistemas de produção. Brasília: IICA: EMBRAPA-CNPGL, 1986. 197p.

GUY, J.H; ROWLINSON, P.; CHADWICK, J.P et al. Behaviour of two genotypes of growing-finish pig in three different housing system. Applied Animal Behaviour Science, v.75, n.3, p.193-206, 2002.

HAYDOCK, K.P.; SHAW, N.H. The comparative yield method for estimating dry matter yield of pasture. Australian Journal Experimental Agriculture and Animal Husbandry, v. 15, p.663-670,1975.

IRGANG, R.; SOUZA, J.M.; CARDOSO, S. et al. Desempenho de suínos mestiços criados em confinamento e a campo. Revista da Sociedade Brasileira de Zootecnia, v.21, n.4, p.718-729, 1992.

LAVORENTI, A.; PACHECO, C.R.V.M.; MIYDA, V.S. et al. Perfomance e qualidade de carcaça de suínos criados em confinamento e em pastagem. O solo, v.72, n.2, p.19-24, 1980.

MOOT, G.O.; LUCAS, H.L. The design conducted and interpretation of grazing trials on cultivated and improved pasture. In: INTERNATIONAL GRASSLAND CONGRESS, 6., 1952, Pensilvânia. Proceedings... Pensilvânia: State College Press, 1952. p.1380-1395.

MOTT, G.O.; BARNHART, C.E. Utilizacion de las forrajes por los cerdos. In: HUGHES, H.D.; HEATH, M.E.; METCALFE, D.S. (Eds.) Forrajes. México: Editorial Continental, 1966. p.707-715.

NATIONAL RESEARCH COUNCIL - NRC. Nutrient requeriment of swine. 10.ed.rev. Washington, D.C.: National Academy Press, 1998. $210 \mathrm{p}$.

ROPPA, L. A nutrição e a alimentação das fêmeas reprodutrizes. In: CONGRESSO BRASILEIRO DE REPRODUÇÃO ANIMAL, 9, Belo Horizonte, 1991. Anais... Belo Horizonte: 1991. p.217-247.

STATISTICAL ANALYSES SYSTEM - SAS. SAS/STAT version 6.12. Cary: 1996. 1680p.

SÓRIO JR., H. Pastejo voison: teorias-práticas-vivências. Passo Fundo: Universidade de Passo Fundo, 2003. 408p.

STERN, S.; ANDRESEN, N. Performance, site preferences, foraging and excretory behaviour in relation to feed allowance of growing pigs on pasture. Livestock Production Science, v.79, n.2, p.257-265, 2003.

VICENZI, M.L. Implantação, tipos e manejo da cobertura vegetal em "Sistema Intensivo de Suínos Criados ao Ar Livre". In: SIMPÓSIO SOBRE SISTEMA INTENSIVO DE SUÍNOS CRIADOS AO AR LIVRE - SISCAL, 1996, Concórdia. Anais... Concórdia: 1996. p.43-57. 